U.S. DEPARTMENT OF THE INTERIOR

U.S. GEOLOGICAL SURVEY

\title{
GEOLOGIC MAP OF THE VALENTINE SOUTHEAST QUADRANGLE, MOHAVE COUNTY, ARIZONA
}

\author{
By L. Sue Beard and Ivo Lucchitta
}




\section{GEOLOGIC MAP SYMBOLS}

COMMONLY USED ON MAPS OF THE UNITED STATES GEOLOGICAL SURVEY

(Special symbols are shown in explanation)

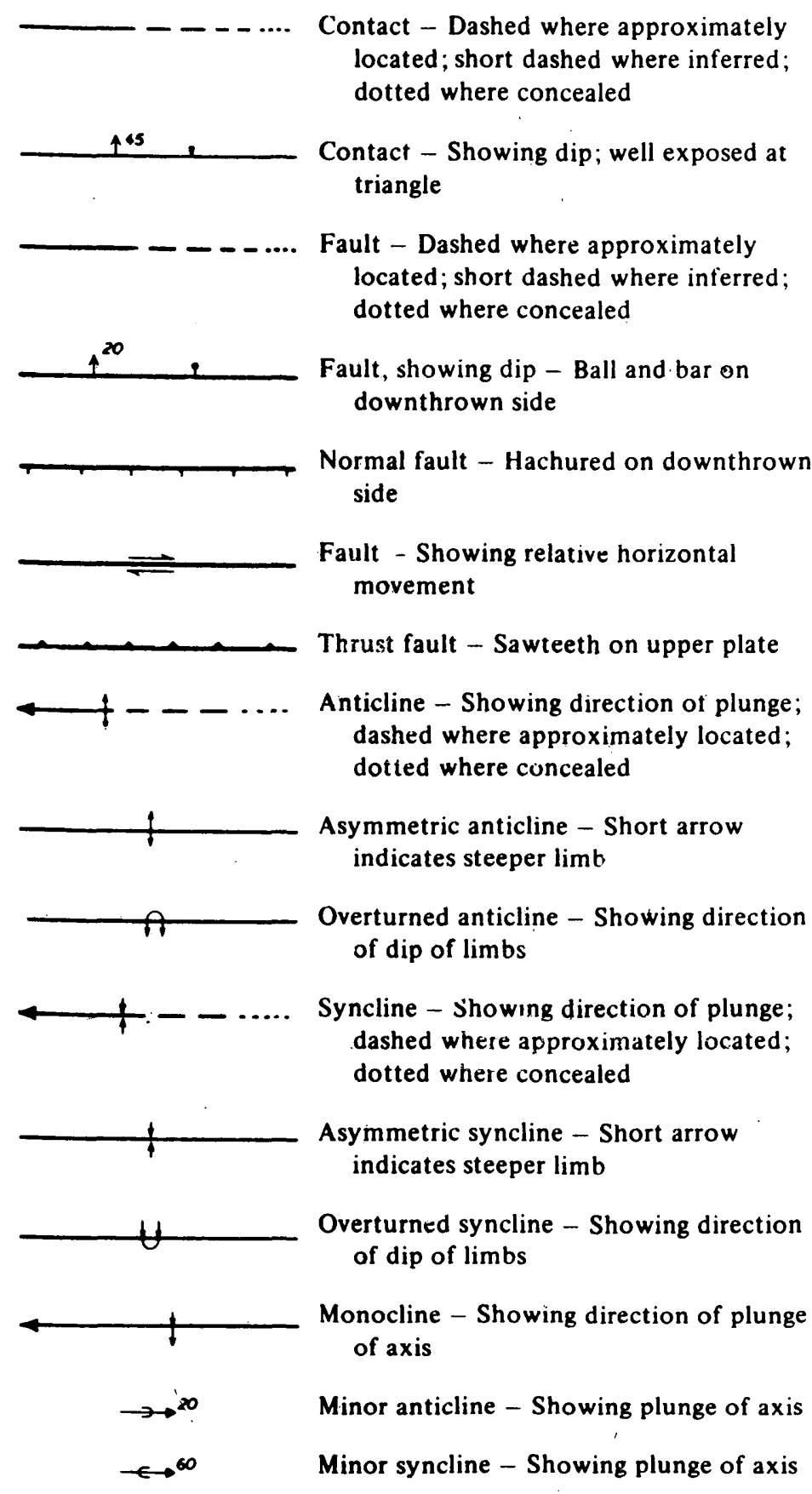

Strike and dip of beds - Ball indicates top of beds known from sedimentary structures

10 Inclined $\oplus$ Horizontal

+ Vertical $\stackrel{40}{\longrightarrow}$ Overturned

Strike and dip of foliation

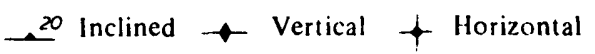

Strike and dip of cleavage

${ }^{15}$ Inclined $\rightarrow$ Vertical $f$ Horizontal

Bearing and plunge of lineation

$15 \longleftarrow$ Inclined $\bullet$ Vertical $\longleftrightarrow$ Horizontal

Strike and dip of joints

.. .40 Inclined $\rightarrow$ Vertical + Horizontal

Note: planar symbols (strike and dip of beds, foliation or schistosity, and cleavage) may be combined with linear sy mbols to record data observed at same locality by superimposed symbols at point of observation. Coexisting planar symbols are shown intersecting at point of observation.

Shafts

๑ Vertical $\$$ Inclined

Adit, tunnel, or slope

$\succ$ Accessible \& Inaccessible

x Prospect

Quarry

x Active Abandoned

Gravel pit

$x$ Active $\quad x$ Abandoned

Oil well

- Drilling $\phi$ Shut-in $\phi$ Dry hoie

* Gas Show of gas abandoned

- Oil Show of oil 